Preferences for contralateral prophylactic mastectomy

\title{
My mind is made up: cancer concern and women's preferences for contralateral prophylactic mastectomy
}

Running Title: Preferences for contralateral prophylactic mastectomy

Richard De Abreu Lourenço ${ }^{1}$, Marion Haas ${ }^{1}$, Jane Hall ${ }^{1}$, Kim Parish ${ }^{2}$, Domini Stuart ${ }^{2}$, Rosalie Viney ${ }^{1}$.

1 Centre for Health Economics Research and Evaluation, University of Technology Sydney PO Box 123

2

Broadway NSW 2007 Australia

Breast Cancer Network Australia

293 Camberwell Rd

Camberwell VIC 3124 Australia

Corresponding Author:

Richard De Abreu Lourenço, $\mathrm{PhD}$

ORCID: 0000-0002-5978-8774

Associate Professor

Centre for Health Economics Research and Evaluation

PO Box 123

Broadway NSW 2007 Australia

Email: Richard.deabreulourenco@,chere.uts.edu.au

Keywords: preferences; risk recurrence; cancer concern; contralateral prophylactic mastectomy; breast cancer; discrete choice experiment.

Research Support: This research was completed as part of a PhD program for R De Abreu Lourenco. R De Abreu Lourenco was the recipient of a University of Technology Sydney (UTS) Business School PhD Scholarship. The following author(s) are employed by UTS: R De Abreu Lourenco, M Haas, J Hall and R Viney. R De Abreu Lourenco, M Haas, J Hall and R Viney also receive funding from Cancer Australia for the provision of health economic support services via the Cancer Research Economics Support Team.

Acknowledgements: Breast Cancer Network Australia (BCNA) provided access to consumer representatives to participate in the design, conduct and interpretation of the results of this study. Women who participated in the qualitative research used as part of this study were recruited via the BCNA Review and Survey Group. We would like to thank all the women who participated in the qualitative and quantitative components of this study. Thanks to Patsy Kenny and Rosemary Hannan for facilitating the qualitative research and assisting with the interpretation of those results.

Disclosures: This study was approved by the UTS Human Research Ethics Committee (UTS HREC No 2015000161). All participants consented to participation in this study by virtue of completion of the online survey. Specific individual consent was obtained from women who participated in the qualitative research informing this DCE. The authors of this paper had full access to all the data and supporting reference materials used in the preparation of the manuscript. The results reported in this paper are drawn from a survey developed by the research team. While this survey included some demographic questions which have appeared in other surveys, it largely comprised new questions. Reasonable requests to the corresponding author for a copy of the survey questionnaire will be considered. 


\begin{abstract}
The fear of cancer recurrence is cited as a motivator of women's preferences between routine monitoring or contralateral prophylactic mastectomy (CPM) as methods of managing ongoing breast cancer risk. We conducted a discrete choice experiment among a general community sample of women who completed 12 hypothetical choices between routine monitoring or CPM described by aspects of treatment efficacy, safety, cost and involvement in decision making. Respondents also completed a modified cancer worry question to assess cancer concern.
\end{abstract}

$57.5 \%$ of 464 women always chose one option, typically routine monitoring. The majority $(71.5 \%)$ reported being concerned about cancer recurrence when completing choice tasks. Latent class analysis identified three groups: preferred routine monitoring; preferred CPM; and 'traders' (willing to swap between options). Among traders, women were less likely to choose an option associated with higher risk of recurrence. Women were more likely to choose options associated with less intrusive monitoring methods and where they were involved in decision-making. Women concerned about cancer recurrence were more likely to choose CPM over monitoring.

This study shows that women's preferences about how to manage breast cancer recurrence risk reflect the importance of the associated health effects, experience of care and attitudes to cancer recurrence. 


\section{Introduction}

In a Consensus Statement, the American Society of Breast Surgeons highlighted that growth in the use of contralateral prophylactic mastectomy (CPM) has been in part driven by the preferences of women with breast cancer (J. C. Boughey, Attai, Chen, Cody, Dietz, Feldman, Greenberg, Kass, Landercasper, Lemaine, MacNeill, Song, et al., 2016). The Society and others (J. Boughey et al., 2010; J. C. Boughey, Attai, Chen, Cody, Dietz, Feldman, Greenberg, Kass, Landercasper, Lemaine, MacNeill, Margenthaler, et al., 2016; J. C. Boughey, Attai, Chen, Cody, Dietz, Feldman, Greenberg, Kass, Landercasper, Lemaine, MacNeill, Song, et al., 2016; Fayanju, Stoll, Fowler, Colditz, \& Margenthaler, 2014; Fisher et al., 2012; Lostumbo, Carbine, \& Wallace, 2010; Rosenberg et al., 2013; Sando et al., 2018; Spillaine, 2016; Tuttle, Abbott, Arrington, \& Rueth, 2010) note that, for some women, these preferences reflect a desire to reduce the fear or anxiety associated with cancer recurrence. The choice to undergo CPM might also reflect a woman's preferences regarding followup breast cancer care, in particular, complying with intensive monitoring regimens, or the influence of follow-up care on body image and sexual identity (Rosenberg et al., 2013; Spillaine, 2016).

CPM has been shown to be associated with increases in health care use, largely due to the associated surgery and subsequent breast reconstruction (Deshmukh et al., 2014). As this increased use of health care does not necessarily improve breast cancer health outcomes (J. C. Boughey, Attai, Chen, Cody, Dietz, Feldman, Greenberg, Kass, Landercasper, Lemaine, MacNeill, Song, et al., 2016; Pauker \& Alseiari, 2014; Spillaine, 2016), there is a need to better understand what is influencing women's preferences and values for CPM. One way to understand such preferences is through the use of discrete choice experiments (DCE). DCEs are a widely used technique in marketing, environmental and transport economics that are being increasingly applied to choices in health care (Clark, Determann, Petrou, Moro, \& de Bekker-Grob, 2014). In a DCE the intervention of interest is described by its characteristics, called attributes e.g. cancer risk. A survey is constructed that presents respondents with a series of choice sets described by one or more choice profiles, which present hypothetical but realistic combinations of these attributes. Within each choice set, survey respondents are asked to make choices about which profile they would choose. Analysis of these repeated choices and how respondents trade-off their choices between profiles reveals the value individuals place on specific attributes (A. Muhlbacher \& F. R. Johnson, 2016).

In this study, we used a DCE to understand what influenced the preferences of a general community sample of women for the management of the risk of cancer recurrence in the context of early breast cancer. We examined how women's choices between profiles describing routine monitoring and the use of CPM following treatment for early breast cancer were affected by the attributes describing those profiles, as well as by their demographic characteristics and concerns regarding cancer recurrence. The results presented in this paper focus on the key factors influencing women's choices and what influence concern about cancer recurrence has on decisions regarding the management of breast cancer risk.

\section{Methods}

\section{DCE Design}

The attributes and levels included in the DCE survey were developed using information from the existing literature on breast cancer (Benning, Kimman, Dirksen, Boersma, \& Dellaert, 2012; Bessen et al., 2014; J. Boughey et al., 2010; Fallowfield, McGurk, \& Dixon, 2004; Kimman, Dellaert, Boersma, Lambin, \& Dirksen, 2010; Rosenberg et al., 2013; Yi et al., 2010) and the results of qualitative research with two groups of women who had previously undergone treatment for early 
stage breast cancer $(n=11)$. While the choices of some participants in those focus groups centred on reducing the likelihood of future cancer recurrence, others focussed on the process of care - reflected in a lack of trust in the standard methods of monitoring, or avoidance of the intrusiveness of ongoing monitoring e.g. mammography, and the negative effects of surgical intervention (such as pain and the loss of breast sensitivity). One of the key themes that emerged was the influence on women's decisions of anxiety associated with a fear of cancer recurrence and anticipatory anxiety associated with testing of the unaffected breast; some women described a desire to reduce anxiety or a fear of recurrence as motivators for their decision to have a CPM.

In developing the attributes for the DCE, it was not considered possible to conceptualise an attribute that directly conveyed fear of recurrence or anticipatory anxiety because these reflect a respondent's individual perceptions. Rather, these effects were incorporated via attributes describing the likelihood of future cancer (the risk of contralateral breast cancer and the risk of ipsilateral or metastatic breast cancer, as measures of fear of recurrence) and the mode and frequency of ongoing monitoring (for anticipatory anxiety). The other attributes included were: the risk of pain; the risk of losing breast sensitivity; involvement in decision making; and out-of-pocket (OOP) costs for routine monitoring and CPM surgery. Three attributes, risk of pain, risk of losing breast sensitivity and OOP for CPM surgery, were specific to the CPM option (see Table 1). The range of attributes and possible levels were refined following a pilot survey with 87 women recruited from an online general community panel provider (PureProfile, 2014).

The total number of intervention profiles that could be described by the combination of these attributes was prohibitively large (over 55,000). Accordingly, these were reduced to a manageable number that was also mathematically efficient (a C-efficient design was used to it minimised the variance of the ratio of how women responded to the cost of monitoring and any other attribute), using the computer design program Ngene and the choice values obtained from the pilot study (A. Muhlbacher \& F. Johnson, 2016; Rose, Collins, Bliemer, \& Hensher, 2012). This resulted in a design that comprised a total of 48 choice sets, with each respondent randomly allocated to see 12 . In each choice set, respondents chose between two methods of managing ongoing breast cancer recurrence risk, labelled as 'Surgery to remove unaffected breast plus monitoring' and 'Routine monitoring only'. The design of this experiment meant that the choice profiles were "labelled" since some attribute levels only appeared in one option e.g. surgical OOP costs were only relevant for the CPM option, thus respondents were effectively not blinded to the profiles. An example of a choice set, including the choice labels, is provided at Box 1.

Each survey also included a background vignette describing the choice scenario. Respondents were randomised to three versions of the survey to test the influence on women's choices of varying how the risks of cancer recurrence were presented and the amount of information in the background vignette. The allocation of respondents to versions was balanced, and subsequent testing showed that the results could be combined across versions (results available on request). The results presented in this paper are from the pooled analysis.

\section{Cancer Concern and Demographics}

In addition to completing all 12 choice sets, respondents were also asked to answer demographic questions and to rate the extent to which they were concerned about the choice attributes while they were completing the survey. Based on a modified cancer worry scale (Campbell, Marbella, \& Layde, 2000; Custers et al., 2014; Spencer et al., 1999; Thewes et al., 2012), respondents were asked to rate each of the choice attributes (cancer recurrence, costs of care, the type and frequency of monitoring, pain or loss of breast sensitivity, and involvement in decision making) against the question: "How 
much did concern or worry about each of the following factors influence the choices you made?" Responses were rated on a five-point scale from not at all (1) to extremely (5) concerned; ratings from 1-3 were categorised as being not concerned about an attribute, and ratings of 4-5 were categorised as concerned. While concern about cancer recurrence was the primary measure of interest for this question, the other four factors were included to reduce the potential for respondents to unduly focus on cancer recurrence in their responses. The demographic characteristics for respondents classified as being concerned and not concerned were summarised and compared using Fisher's $\mathrm{Chi}^{2}$ test.

\section{Analysis of Results}

Typically, the analysis of DCE surveys assesses the relationship between the choices respondents make and the differences in the attributes that were used to describe profiles resulting in those choices (Greene, 2008; Johnson et al., 2013; A. Muhlbacher \& F. Johnson, 2016). Based on the results of the qualitative research and pilot survey, we hypothesised that we could categorise women into groups based on the similarity of their preferences, or how they made choices, between routine monitoring and CPM. Given the potential for such groups to exist, we used latent class analysis (Pacifico \& Yoo, 2013), similar to cluster analysis, to analyse the choices women made. This assumes that the probability an individual will choose a particular option is conditional on them belonging to a particular group and is a widely-used in the analysis of choices in health care (Zhou, Thayer, \& Bridges, 2018). The latent class analysis tested the likelihood that women belonged to a given group based on their demographic characteristics (age, household income, education), whether they were concerned about cancer recurrence when completing the choice tasks, their prior participation in cancer screening, and accounting for the pooled nature of the survey. The specification of this analysis is described in the technical appendix. The resulting coefficients from this analysis, which show the strength of preference for attributes influencing choice, are reported as odds ratios (OR). All analyses were conducted using Stata 12.

\section{Respondent Recruitment}

Both the pilot and final surveys were administered online to women aged 18 years or older registered with the online panel company PureProfile (PureProfile, 2014). Women were recruited to the survey by means of an invitation sent directly to each potential respondent's PureProfile home page; participation was by self-selection. PureProfile was reimbursed per respondent (approximately $\$ 10$ 15 per survey), part of which was passed onto respondents. This study was approved by the UTS Human Research Ethics Committee (HREC 2015000161).

\section{Results}

\section{The Participants}

A total of 464 respondents completed the survey (Table 2). Compared to the Australian population a higher proportion of respondents were in the middle age groups and better educated; however, respondents were similar to the Australian population in terms of income and geographic location (Australian Bureau of Statistics (ABS), 2015a, 2015b, 2015c). Respondents' participation in all types of cancer screening, in all age groups, was less than $40 \%$ when restricted to the previous two-year period - the interval of interest for both the National Cervical Screening and Breast Cancer Screening programs in Australia. This is lower than screening participation among the general population of Australian women; data from the Australian Institute of Health and Welfare show that $54 \%$ of women aged 50-69 had a mammogram, 57\% of those aged 20-69 had a Pap test, and 38.5\% of those aged 5065 had been screened for bowel cancer in the last two years (Australian Institute of Health and 
Welfare, 2014, 2016). Lower rates of screening participation among survey respondents suggests that, compared to the general population of Australian women, they might be willing to accept more risk as it pertains to cancer, or are less concerned about cancer occurrence.

\section{Attribute Importance and Concern}

Respondents rated the risk of recurrence of contralateral (22.6\%) and ipsilateral/metastatic (18.7\%) breast cancer as the two most important attributes affecting their choices, while the risk of losing breast sensitivity $(28.7 \%)$ was the least important.

Most respondents (71.5\%) reported being concerned about cancer recurrence when completing the choice tasks. Respondents were either not concerned about the remaining attributes, or the numbers of respondents concerned or not concerned about individual attributes were approximately equal. Women reporting concern about cancer recurrence differed from those not concerned in terms of all the demographic factors included (age, income, education, region of residence $-\mathrm{p}<0.001$ for all factors). In particular, more respondents who were concerned about recurrence had a university degree $(32.5 \%)$ compared with those who were not concerned (26.5\%), with corresponding differences in the proportion of those with a vocational education ( $36.2 \%$ and $45.4 \%$ respectively). In addition, a higher proportion of respondents who were concerned about cancer recurrence (68.7\%) lived in a major city compared with those who were not concerned (63.1\%). Ratings of attribute importance differed between respondents based on cancer concern: those who were concerned rated the risk of recurrence (CBC or Other risk) as most important, while respondents who were not concerned about cancer recurrence, reported that the most important attribute was involvement in decision-making (see Figure 1). Both groups rated the risk of losing breast sensitivity as the least important attribute.

\section{Choice Behaviour}

An interesting feature of this choice experiment is that the majority of respondents (57.5\%) always chose one option, typically routine monitoring (49.1\%), with fewer preferring CPM (8.4\%). In DCE parlance, this is referred to as 'non-trading'. Based on standard information criteria (Pacifico \& Yoo, 2013), the latent class analysis identified three groups of respondents: Prefer CPM ( $12 \%$ of women) who indicated a preference for CPM in the majority of choices; Prefer Monitoring (59\%) who preferred routine monitoring in the majority of choices; and Traders (29\%) who were prepared to swap between CPM and routine monitoring. The factors influencing choice as described by the latent class analysis are reported in Table 3.

Respondents in the Prefer CPM group were influenced by the alternative specific constant (management compared with $\mathrm{CPM} ; \mathrm{OR}=0.24, \mathrm{p}=0.073$ ), indicating that they were more likely to choose CPM than routine monitoring. Respondents in the Traders group were not influenced by the alternative specific constant $(\mathrm{p}=0.291)$, but were less likely to choose options with higher breast cancer risk $(\mathrm{OR}=0.81, \mathrm{p}<0.001$ for contralateral risk; $\mathrm{OR}=0.96, \mathrm{p}=0.01$ ipsilateral $/$ metastatic risk $)$, pain risk $(\mathrm{OR}=0.99, \mathrm{p}=0.02)$, or monitoring $(\mathrm{OR}=0.95, \mathrm{p}<0.001)$ and surgical $\mathrm{OOP}$ costs $(\mathrm{OR}=0.99$, $\mathrm{p}<0.001)$. They were more likely to choose options in which they were always involved in decisions about their care $(\mathrm{OR}=1.14, \mathrm{p}=0.001)$. Finally, respondents in the Prefer Monitoring group showed a strong preference for routine monitoring indicated by the significant $\mathrm{OR}$ for the alternative specific constant $(\mathrm{OR}=5.26, \mathrm{p}<0.01)$. Despite strong preferences for routine monitoring, some respondents in this group were less likely to choose options with higher monitoring costs $(\mathrm{OR}=0.91, \mathrm{p}=0.032)$ and surgical OOP costs $(\mathrm{OR}=0.99, \mathrm{p}=0.008)$, the latter applying to the CPM option only. 
Inclusion of the demographic variables in the factors determining class membership showed that overall, respondents were less likely to belong to either the Prefer CPM $(\mathrm{OR}=0.043, \mathrm{p}<0.001)$ or Traders groups $(\mathrm{OR}=0.343, \mathrm{p}<0.001)$ than the Prefer Monitoring group. Younger respondents (aged 16-25 years) were more likely than those aged 25-45 to be Traders compared to Prefer Monitoring, while those 45-65 years of age were more likely than 25-45 year olds to Prefer CPM compared with Prefer Monitoring. In general, respondents who were cancer concerned were less likely to be in the Prefer Monitoring group compared with either of the other two groups $(\mathrm{p}<0.001)$.

\section{Discussion}

There is often discussion in the popular and academic press about the importance of early detection and treatment as a means of reducing the effects of breast cancer. Early detection and treatment of recurrence is also important for women who have experienced breast cancer; how women choose to manage their ongoing risk of recurrence has implications not only for their risk of cancer recurrence, but also for their ongoing experience of care, and the subsequent utilisation and costs of that care. The importance of these issues was discussed by women participating in the qualitative work underpinning this research and is consistent with the results of previous research regarding the factors motivating women's decisions about CPM (Altschuler et al., 2008; Fisher et al., 2012; Rosenberg et al., 2013; Sando et al., 2018).

In a recently published cohort study of outcomes in early-onset breast cancer, Copson et al (2018) concluded that decisions regarding risk reducing strategies, such as CPM, should not only take into account ongoing cancer risk but also patient preferences (Copson et al., 2018). Our results show that a majority of women have strongly held preferences; they favour routine monitoring when choosing how they would manage the ongoing risk of cancer recurrence. It is possible that this reflects a willingness among these women to accept more risk as it pertains to cancer recurrence. The fact that women in our study reported lower rates of participation in national cancer screening programs than those of a similar age suggests that they may be willing to accept higher cancer risks than the general population of Australian women.

Other women in our sample were more willing to swap between management options, their decisions most often motivated by a desire to avoid higher risks of breast cancer, or to be involved in decisionmaking. While there is a growing interest in the importance of meta-health effects such as convenience (De Abreu Lourenço, 2017), in this study, health effects dominated. That dominance may reflect a response to underlying concerns regarding cancer recurrence, and thus reflect a level of reassurance that health measures provide to women in terms of avoiding future cancer risks. It is also possible that the dominance of health effects was a result of respondents adopting simplifying heuristics in their decision-making. Each choice profile contained nine attributes, which might have led some respondents to focus only on those attributes they considered important. Constructing DCE designs with attributes in overlapping subsets has been used to test the impact of up to 30 attributes in a choice context (A. Muhlbacher \& F. Johnson, 2016). An overlapping design was not used in this study due to the likelihood that it would require a much larger sample size. In the pilot study, $72 \%$ of respondents indicated that the number of attributes did not influence how they answered the choice tasks. Thus, taking this into account, and that three attributes applied only to the CPM option, it is unlikely that the number of attributes adversely affected the results observed.

Our results indicated that the most important difference between traders and non-traders was the extent to which they reported being concerned about cancer recurrence; women who were concerned about cancer recurrence were more likely to trade and generally more likely to prefer CPM over monitoring. In contrast, women who were not concerned about cancer recurrence reported that being 
involved in decision making about their care was more important. Overall, women were more likely to choose options in which they were involved in decisions about their care, supporting the calls made by Boughey et al. (2016) for shared decision-making in this setting (J. C. Boughey, Attai, Chen, Cody, Dietz, Feldman, Greenberg, Kass, Landercasper, Lemaine, MacNeill, Margenthaler, et al., 2016). All respondents indicated that health effects affected their choices, highlighting the importance of providing women with adequate information about the potential health effects associated with the available options for managing the risk of breast cancer recurrence. That information may have to be tailored to women's underlying attitudes to the risk of cancer recurrence, particularly in light of the potential for the lack of information on breast cancer risk management to impact on fear of cancer recurrence (Fardell et al., 2016).

In this study, latent class analysis was used to identify groups which behaved most similarly in terms of their choices. Such analysis is a potentially powerful means of describing groups displaying similar choice behaviour, but, as yet, it is used in less than half of published studies in health care (Zhou et al., 2018).

One potential limitation of our study is that it did not include a specific sample of women with experience of breast cancer. While acknowledging the usefulness of such a sample, we believe their exclusion does not diminish the validity of the results given that respondents may be faced with a future choice regarding the ongoing management of breast cancer risk. The salience of this research was enhanced through the inclusion of women with experience of breast cancer in its development, conduct and interpretation. In addition, we deliberately excluded a scenario in which women were making choices about breast cancer risk in light of a familial or genetic predisposition; in our opinion this represents a different decision context, potentially giving rise to a different set of preferences.

We observed a high degree of non-trading, largely in favour of routine monitoring over CPM. The source of such strong preferences appears to lie in what women understood by the labels we used to describe the management options of routine monitoring and CPM. However, it cannot be discounted that some women were motivated to always choose monitoring because there were some attributes (surgical OOP, pain risk and sensitivity risk) that applied only to the CPM option. However, because we did not collect specific qualitative data regarding this issue, it was not possible to explore with the women who exhibited such strong preferences what motivated their particular choices. It is also possible that women were influenced in their choices by the wording used to label our choice options; preliminary pilot and qualitative testing indicated that the wording used in the survey was acceptable to women, but we did not explore the extent to which respondents might have inferred meaning in the labels beyond what was expressed in the attributes shown. It is also possible that the choices made by some women may have differed if we had included the risk of lymphedema as an attribute, noting that lymphedema risk more commonly affected by the method of lymph node dissection during mastectomy and has a low incidence among women undergoing contralateral prophylactic mastectomy (Geiger et al., 2005; Miller et al., 2012).

While there have been other DCEs conducted in the field of breast cancer, they have focused on preferences for the provision of screening services, follow-up care or surgery (Bessen et al., 2014; Caldon, Walters, Ratcliffe, \& Reed, 2007; Gerard, Shanahan, \& Louviere, 2003). This is the first research to evaluate women's preferences for how to manage the risks of breast cancer recurrence using a DCE, and the first to use a latent class analysis in this setting. We have not only been able to describe differences in the choice behaviour of groups of women, but importantly how these groups differ in terms of their demographic characteristics. Importantly, this included investigating whether choices differed depending on whether or not women were concerned about cancer recurrence. This revealed differences across women in terms of the importance to them of achieving reductions in 
cancer risk - those who were concerned over cancer recurrence had stronger preferences for management strategies associated with lower ongoing risks. Previous research has found high levels of health care utilisation among patients who exhibit high levels of concern about disease symptoms or illness (Barsky, Orav, \& Bates, 2005; Bermingham, Cohen, Hague, \& Parsonage, 2010; Mewton \& Andrews, 2013; Puri \& Dimsdale, 2011). It is plausible that women who are concerned about cancer recurrence following breast cancer treatment might use more health care services than those who are not similarly concerned. This is a topic worth exploring in future research.

\section{Conclusion}

This is the first DCE to investigate women's preferences for managing ongoing breast cancer risk and to consider the role of cancer concern in shaping those preferences. The research identified that women's preferences about how to manage breast cancer recurrence risk reflect the importance of the associated health effects (avoiding ongoing cancer risk), the experience of care (less frequent and less invasive monitoring) and attitudes to cancer recurrence (those who were concerned about cancer recurrence were least likely to prefer ongoing monitoring as a management option). Understanding that preferences differ based on women's level of concern about cancer recurrence can be used to shape the information provided to them when management options are discussed. 


\section{Technical Appendix}

The underlying principle behind DCEs is that goods or services are comprised of attributes, and individuals making a choice between those goods or services choose the combination of attributes they expect to deliver the highest utility.(Lancaster, 1966) In its simplest form, those choices can be investigated using the following relationship (Keane \& Wasi, 2013; McFadden, 1974)

$U_{i j t}=\beta x_{i j t}+\varepsilon_{i j t} U_{\mathrm{ijt}}=\beta \mathrm{x}_{\mathrm{ijt}}+\varepsilon_{\mathrm{ijt}}$

where $U$ reflects the utility, or satisfaction, derived by individual $i$ over alternative $j$ at choice $t, x$ are the attributes describing the choices and covariates expected to influence choice, and $\beta$ is the vector of homogenous attribute coefficients: it can vary between attributes, but for a given attribute is assumed to be the same across individuals. This analysis can also include variables for the choice labels (alternative specific constants; which in our analysis were the labels for profiles describing CPM plus monitoring, or monitoring only) as explanatory covariates.(Keane \& Wasi, 2013) In analysing these choices we are determining the probability that an individual $i$ will choose an alternative $j$ at each choice $t$, given the attribute levels $x$ describing that choice. The base model, in (1), assumes homogeneity across individuals in determining their preferences, and thus probability of making a given choice. However, based on the results of the qualitative research and preliminary pilot survey, we hypothesised that we could categorise respondents into groups based on their preferences between routine monitoring and $\mathrm{CPM}$.

Accordingly, we used latent class analysis(Pacifico \& Yoo, 2013) to investigate the choices respondents made, taking into account the potential for respondents to be characterised into separate groups based on the similarity of their choice behaviour. The choice probabilities are thus estimated according to the following:

$\mathrm{P}(\mathrm{j} / \mathrm{g})=\exp \left(\beta_{\mathrm{g}} \mathrm{x}_{\mathrm{ijt}}\right) / \sum_{\mathrm{j}=1}^{2} \exp \left(\beta_{\mathrm{g}} \mathrm{x}_{\mathrm{ijt}}\right)$

where the interpretation of $x$ and $\beta$ remains as previously, and the probability of an individual choosing option $j$ is conditional on their membership of group $g$; there are 1 to $\mathrm{G}$ groups to be determined by the model performance criteria, and the attribute coefficients vary between groups (Keane \& Wasi, 2013). 


\section{References}

Altschuler, A., Nekhlyudov, L., Rolnick, S. J., Greene, S. M., Elmore, J. G., West, C. N., . . Geiger, A. M. (2008). Positive, negative, and disparate--women's differing long-term psychosocial experiences of bilateral or contralateral prophylactic mastectomy. Breast J, 14(1), 25-32. doi:10.1111/j.1524-4741.2007.00521.x

Australian Bureau of Statistics (ABS). (2015a). Australian Demographic Statistics. 3101.0. Retrieved from http://www.abs.gov.au/AUSSTATS/abs@.nsf/DetailsPage/3101.0Jun\%202015?OpenDocume $\underline{\mathrm{nt}}$

Australian Bureau of Statistics (ABS). (2015b). Education and Work, Australia, May 2015. 6227.0. Retrieved from http://www.abs.gov.au/AUSSTATS/abs@.nsf/DetailsPage/6227.0May\%202015?OpenDocum ent

Australian Bureau of Statistics (ABS). (2015c). Measures of Australia's Progress, 2013 1370.0. Retrieved from http://www.abs.gov.au/ausstats/abs@.nsf/Lookup/by\%20Subject/1370.0 2013 Download\%2 0Summary Data\%20and\%20downloads 10

Australian Institute of Health and Welfare, A. ( 2014). National Bowel Cancer Screening Program Monitoring report 2013-14

Australian Institute of Health and Welfare, A. ( 2016). Cancer screening programs in Australia.

Retrieved from http://www.aihw.gov.au/cancer/screening/

Barsky, A., Orav, E., \& Bates, D. (2005). Somatization increases medical utilization and costs independent of psychiatric and medical comorbidity. Arch Gen Psychiatry, 62(8), 903-910.

Benning, T. M., Kimman, M. L., Dirksen, C. D., Boersma, L. J., \& Dellaert, B. G. (2012). Combining individual-level discrete choice experiment estimates and costs to inform health care management decisions about customized care: the case of follow-up strategies after breast cancer treatment. Value Health, 15(5), 680-689. doi:10.1016/j.jval.2012.04.007

Bermingham, S. L., Cohen, A., Hague, J., \& Parsonage, M. (2010). The cost of somatisation among the working-age population in England for the year 2008-2009. Mental Health in Family Medicine, 7(2), 71-84.

Bessen, T., Chen, G., Street, J., Eliott, J., Karnon, J., Keefe, D., \& Ratcliffe, J. (2014). What sort of follow-up services would Australian breast cancer survivors prefer if we could no longer offer long-term specialist-based care? A discrete choice experiment. Br J Cancer, 110(4), 859-867. doi:10.1038/bjc.2013.800

Boughey, J., Hoskin, T., Degnim, A., Sellers, T., Johnson, J., Kasner, M., . . Frost, M. (2010). Contralateral prophylactic mastectomy is associated with a survival advantage in high=-risk women with a personal history of breast cancer. Ann Surg Oncol, 17(17), 2702-2709.

Boughey, J. C., Attai, D. J., Chen, S. L., Cody, H. S., Dietz, J. R., Feldman, S. M., . . Yao, K. A. (2016). Contralateral Prophylactic Mastectomy Consensus Statement from the American Society of Breast Surgeons: Additional Considerations and a Framework for Shared Decision Making. Ann Surg Oncol, 23(10), 3106-3111. doi:10.1245/s10434-016-5408-8

Boughey, J. C., Attai, D. J., Chen, S. L., Cody, H. S., Dietz, J. R., Feldman, S. M., . . Margenthaler, J. A. (2016). Contralateral Prophylactic Mastectomy (CPM) Consensus Statement from the American Society of Breast Surgeons: Data on CPM Outcomes and Risks. Ann Surg Oncol, 23(10), 3100-3105. doi:10.1245/s10434-016-5443-5

Caldon, L. J., Walters, S. J., Ratcliffe, J., \& Reed, M. W. (2007). What influences clinicians' operative preferences for women with breast cancer? An application of the discrete choice experiment. Eur J Cancer, 43(11), 1662-1669. doi:10.1016/j.ejca.2007.04.021

Campbell, B. H., Marbella, A., \& Layde, P. M. (2000). Quality of life and recurrence concern in survivors of head and neck cancer. Laryngoscope, 110(6), 895-906. doi:10.1097/00005537200006000-00003

Clark, M. D., Determann, D., Petrou, S., Moro, D., \& de Bekker-Grob, E. W. (2014). Discrete choice experiments in health economics: a review of the literature. PharmacoEconomics, 32(9), 883902. doi:10.1007/s40273-014-0170-x 
Copson, E., Maishman, T., Tapper, W., Cutress, R., Greville-Heygate, S., Altman, D., . . Eccles, D. (2018). Germline BRCA mutation and outcome in young-onset breast cancer (POSH): a prospective cohort study. Lancet Oncology, Published Online, 12.

Custers, J., van den Berg, S., van Laarhoven, H., Bleiker, E., Gielissen, M., \& Prins, J. (2014). The Cancer Worry Scale: detecting fear of recurrence in breast cancer survivors. Cancer Nursing, 37, E44-50.

De Abreu Lourenço, R. (2017). More than health: the role and value of meta-health effects in health care decisions.

Deshmukh, A. A., Cantor, S. B., Crosby, M. A., Dong, W., Shen, Y., Bedrosian, I., . . Brewster, A. M. (2014). Cost of contralateral prophylactic mastectomy. Ann Surg Oncol, 21(9), 2823-2830. doi:10.1245/s10434-014-3759-6

Fallowfield, L., McGurk, R., \& Dixon, M. (2004). Same gain, less pain: potential patient preferences for adjuvant treatment in premenopausal women with early breast cancer. Eur J Cancer, 40(16), 2403-2410. doi:10.1016/j.ejca.2004.07.013

Fardell, J. E., Thewes, B., Turner, J., Gilchrist, J., Sharpe, L., Smith, A. B., . . Butow, P. (2016). Fear of cancer recurrence: a theoretical review and novel cognitive processing formulation. Journal of Cancer Survivorship, 10(4), 663-673. doi:10.1007/s11764-015-0512-5

Fayanju, O., Stoll, C., Fowler, S., Colditz, G., \& Margenthaler, J. A. (2014). Contralateral prophylactic mastectomy after unilateral breast cancer. Annals of Surgery, 260(6), 1000-1010.

Fisher, C. S., Martin-Dunlap, T., Ruppel, M. B., Gao, F., Atkins, J., \& Margenthaler, J. A. (2012). Fear of recurrence and perceived survival benefit are primary motivators for choosing mastectomy over breast-conservation therapy regardless of age. Ann Surg Oncol, 19(10), 3246-3250. doi:10.1245/s10434-012-2525-x

Geiger, A. M., West, C. N., Harris, E. L., Liu, I.-L. A., Elmore, J. G., Nekhlyudov, L., Fletcher, S. W. (2005). Complications Following Bilateral Prophylactic Mastectomy. JNCl Monographs, 2005(35), 61-66. doi:10.1093/jncimonographs/lgi039

Gerard, K., Shanahan, M., \& Louviere, J. (2003). Using Stated Preference Discrete Choice Modelling to Inform Health Care Decision-Making: A Pilot Study of Breast Screening Participation. Applied Economics, 35(9), 1073-1085. doi:http://www.tandf.co.uk/journals/routledge/00036846.html

Greene, W. (2008). Discrete Choice Modeling. In T. Mills \& K. Patterson (Eds.), The Handbook of Econometrics (Vol. 2). London: Palgrave.

Johnson, F., Lancsar, E., Marshall, D., Kilambi, V., Muhlbacher, A., Regier, D., . . Bridges, J. (2013). Constructing experimental designs for discrete-choice experiments: report of the ISPOR Conjoint Analysis Experimental Design Good Practices Research Task Force. Value in Health, 16, 3-13.

Keane, M., \& Wasi, N. (2013). Comparing alternative models of heterogeneity in consumer choice behavior. Journal of Applied Econometrics, 28, 1018-1045.

Kimman, M. L., Dellaert, B. G., Boersma, L. J., Lambin, P., \& Dirksen, C. D. (2010). Follow-up after treatment for breast cancer: one strategy fits all? An investigation of patient preferences using a discrete choice experiment. Acta Oncol, 49(3), 328-337. doi:10.3109/02841860903536002

Lancaster, K. (1966). A New Approach to Consumer Theory. The Journal of Political Economy, 74(2), 132-157.

Lostumbo, L., Carbine, N., \& Wallace, J. (2010). Prophylactic mastectomy for the prevention of breast cancer. Cochrane Database of Sytematic Reviews, 11.

McFadden, D. (1974). Conditional logit analysis of qualitative choice behavior. In P. Zarembka (Ed.), Frontiers in Econometrics (pp. 105-142). New York: New York: Academic Press.

Mewton, L., \& Andrews, G. (2013). Poor self-rated health and its associations with somatisation in two Australian national surveys. BMJ Open, 3(6), e002965. doi:10.1136/bmjopen-2013-002965

Miller, C. L., Specht, M. C., Skolny, M. N., Jammallo, L. S., Horick, N., O'Toole, J., Taghian, A. G. (2012). Sentinel lymph node biopsy at the time of mastectomy does not increase the risk of lymphedema: implications for prophylactic surgery. Breast cancer research and treatment, 135(3), 781-789. doi:10.1007/s10549-012-2231-1

Muhlbacher, A., \& Johnson, F. (2016). Choice experiments to quantify preferences for health and healthcare: state of the practice. Applied Health Economics and Policy, 14(2), 1-16.

Muhlbacher, A., \& Johnson, F. R. (2016). Choice Experiments to Quantify Preferences for Health and Healthcare: State of the Practice. Appl Health Econ Health Policy. doi:10.1007/s40258-0160232-7 
Pacifico, D., \& Yoo, H. (2013). Iclogit: A Stata command for fitting latent-class conditional logit models via the expectation-maximization algorithm. The Stata Journal, Volume 13 Number 3: pp. (3), 625-639.

Pauker, S. G., \& Alseiari, M. (2014). How big is big enough? Thinking about contralateral prophylactic mastectomy. J Natl Cancer Inst, 106(8). doi:10.1093/jnci/dju175

PureProfile. (2014). Retrieved from http://www.pureprofile.com/au

Puri, P., \& Dimsdale, J. (2011). Healthcare utilization and poor reassurance: potential predictors of somatoform disorders. Psychiatr Clin North Am, 34(3), 525-544.

Rose, J., Collins, A., Bliemer, M., \& Hensher, D. (2012). Ngene. The cutting edge of experimental design for stated choice experiments.: ChoiceMetrics Pty Ltd.

Rosenberg, S. M., Tracy, M. S., Meyer, M. E., Sepucha, K., Gelber, S., Hirshfield-Bartek, J., . . . Partridge, A. H. (2013). Perceptions, knowledge, and satisfaction with contralateral prophylactic mastectomy among young women with breast cancer: a cross-sectional survey. Ann Intern Med, 159(6), 373-381. doi:10.7326/0003-4819-159-6-201309170-00003

Sando, I., Billig, J., Ambani, S., Kraft, C., Kidwell, K., Zhong, L., . . Momoh, A. (2018). An Evaluation of the Choice for Contralateral Prophylactic Mastectomy and Patient Concerns About Recurrence in a Reconstructed Cohort. Annals of Plastic Surgery., 80(4), 333-338.

Spencer, S., Lehman, J., Wynings, C., Arena, P., Carver, C., Antoni, M., . . Ironson, G. (1999). Concerns about breast cancer and relations to psychosocial well-being in a multiethnic sample of early-stage patients. Health Psychology, 18, 159-168.

Spillaine, A. (2016). What is new in the surgical management and prevention of breast cancer. Medical Journal of Australia, 204(8), 311-315.

Thewes, B., Butow, P., Zachariae, R., Christensen, S., Simard, S., \& Gotay, C. (2012). Fear of cancer recurrence: a systematic literature review of self-report measures. Psychooncology, 21(6), 571-587. doi:10.1002/pon.2070

Tuttle, T., Abbott, A., Arrington, A., \& Rueth, N. (2010). The Increasing Use of Prophylactic Mastectomy in the Prevention of Breast Cancer. Current Oncology Reports, 12(1), 16-21. doi:10.1007/s11912-009-0070-y

Yi, M., Hunt, K. K., Arun, B. K., Bedrosian, I., Barrera, A. G., Do, K. A., . . Meric-Bernstam, F. (2010). Factors affecting the decision of breast cancer patients to undergo contralateral prophylactic mastectomy. Cancer Prevention Research (Philadelphia, Pa.), 3(8), 1026-1034. doi:10.1158/1940-6207.CAPR-09-0130

Zhou, M., Thayer, W. M., \& Bridges, J. F. P. (2018). Using Latent Class Analysis to Model Preference Heterogeneity in Health: A Systematic Review. Pharmacoeconomics, 36(2), 175-187. doi:10.1007/s40273-017-0575-4 
Preferences for contralateral prophylactic mastectomy

Table 1: DCE Attributes and Levels

\begin{tabular}{|c|c|c|}
\hline \multicolumn{2}{|l|}{ Attribute } & Levels \\
\hline CBC Risk & $\begin{array}{l}\text { The chance that you will be diagnosed with } \\
\text { cancer in your healthy breast some time in the } \\
\text { next ten years is: }\end{array}$ & $\begin{array}{l}3 \text { in a } 1,000(0.3 \%) \\
10 \text { in a } 1,000(1 \%) \\
20 \text { in a } 1,000(2 \%) \\
50 \text { in a } 1,000(5 \%)\end{array}$ \\
\hline Other BC Risk & $\begin{array}{l}\text { The chance that your original cancer returns or } \\
\text { spreads beyond your breasts some time in the } \\
\text { next ten years is: }\end{array}$ & $\begin{array}{l}100 \text { in a } 1,000(10 \%) \\
150 \text { in a } 1,000(15 \%) \\
200 \text { in a } 1,000(20 \%)\end{array}$ \\
\hline $\begin{array}{l}\text { Monitoring } \\
\text { Type }\end{array}$ & $\begin{array}{l}\text { In addition to your regular self-checks, you } \\
\text { will need to have the following tests: }\end{array}$ & $\begin{array}{l}\text { Mammogram } \\
\text { MRIs of your breast area } \\
\text { Ultrasounds of your breast area }\end{array}$ \\
\hline $\begin{array}{l}\text { Monitoring } \\
\text { Frequency }\end{array}$ & $\begin{array}{l}\text { You are scheduled to have your follow-up tests } \\
\text { every: }\end{array}$ & $\begin{array}{l}\text { Six months } \\
\text { Year } \\
\text { Second year }\end{array}$ \\
\hline $\begin{array}{l}\text { OOP: } \\
\text { Monitoring }\end{array}$ & $\begin{array}{l}\text { The cost for monitoring each year is } \$ 900 \text {, and } \\
\text { you pay: }\end{array}$ & $0,300,600,900$ \\
\hline OOP: Surgical & $\begin{array}{l}\text { The cost for surgery associated with managing } \\
\text { your ongoing risk of cancer recurrence is } \\
\$ 15,000 \text {, and you pay: }\end{array}$ & $0,5000,10000,15000$ \\
\hline Pain Risk & $\begin{array}{l}\text { The chance you will experience ongoing pain } \\
\text { is: }\end{array}$ & $\begin{array}{l}400 \text { in } 1,000(40 \%) \\
300 \text { in } 1,000(30 \%) \\
200 \text { in } 1,000(20 \%) \\
100 \text { in } 1,000(10 \%)\end{array}$ \\
\hline Sensitivity Risk & $\begin{array}{l}\text { The chance you will experience an ongoing } \\
\text { loss of sensitivity in your breast area is: }\end{array}$ & $\begin{array}{l}600 \text { in } 1,000(60 \%) \\
500 \text { in } 1,000(50 \%) \\
400 \text { in } 1,000(40 \%) \\
300 \text { in } 1,000(30 \%)\end{array}$ \\
\hline $\begin{array}{l}\text { Decision } \\
\text { Involvement }\end{array}$ & $\begin{array}{l}\text { Your medical team involves you in ongoing } \\
\text { discussions about managing your risk of } \\
\text { cancer recurrence. }\end{array}$ & $\begin{array}{l}\text { Always } \\
\text { Not very often }\end{array}$ \\
\hline
\end{tabular}

Abbreviations: $\mathrm{BC}$, breast cancer; $\mathrm{CBC}$, contralateral breast cancer; OOP, out-of-pocket 
Preferences for contralateral prophylactic mastectomy

Table 2: Respondent demographics

\begin{tabular}{|c|c|c|c|c|}
\hline & \multirow{2}{*}{$\begin{array}{c}\text { Overall Sample } \\
n=464\end{array}$} & \multicolumn{2}{|c|}{ Cancer Concerned } & \multirow{2}{*}{$\frac{\text { Australian }}{\text { Popn. }}$} \\
\hline & & $\begin{array}{c}\text { No } \\
n=130\end{array}$ & $\begin{array}{c}\text { Yes } \\
\mathrm{n}=326\end{array}$ & \\
\hline \multicolumn{5}{|l|}{ Age } \\
\hline $16-24$ & $19(4.09)$ & $6(4.62)$ & $13(3.99)$ & $(15.62)$ \\
\hline $25-44$ & $168(36.21)$ & $47(36.15)$ & $120(36.81)$ & $(34.52)$ \\
\hline $45-64$ & $175(37.72)$ & $50(38.46)$ & $125(38.34)$ & $(30.37)$ \\
\hline $65-74$ & $81(17.46)$ & $21(16.15)$ & $58(17.79)$ & (10.45) \\
\hline 75 or Over & $13(2.8)$ & $5(3.85)$ & $8(2.45)$ & $(9.05)$ \\
\hline Unknown & $8(1.72)$ & $1(0.77)$ & $2(0.61)$ & \\
\hline \multicolumn{5}{|l|}{ Household Income (annum) } \\
\hline Under $\$ 40,000$ & $128(27.59)$ & $37(28.46)$ & $89(27.3)$ & - \\
\hline$\$ 40,000-\$ 79,999$ & $116(25)$ & $31(23.85)$ & $84(25.77)$ & - \\
\hline$\$ 80,000-\$ 149,999$ & $106(22.84)$ & $27(20.77)$ & $79(24.23)$ & - \\
\hline Over $\$ 150,000$ & $34(7.33)$ & $9(6.92)$ & $25(7.67)$ & - \\
\hline Unknown & $80(17.24)$ & $26(20)$ & $49(15.03)$ & - \\
\hline Medianth category & $1,150-1,529$ & $1,150-1,529$ & $1,150-1,529$ & 1,234 \\
\hline \multicolumn{5}{|l|}{ Education } \\
\hline School Only & $136(29.31)$ & $35(26.92)$ & $100(30.67)$ & (42.62) \\
\hline University & $141(30.39)$ & $34(26.15)$ & $106(32.52)$ & (27.54) \\
\hline Vocational & $178(38.36)$ & $59(45.38)$ & $118(36.2)$ & (28.14) \\
\hline Unknown & $9(1.94)$ & $2(1.54)$ & $2(0.61)$ & n.a. \\
\hline \multicolumn{5}{|l|}{ Residence } \\
\hline Major City & $307(66.16)$ & $82(63.08)$ & $224(68.71)$ & (71.30) \\
\hline Inner Regional & $89(19.18)$ & $28(21.54)$ & $59(18.1)$ & $(18.29)$ \\
\hline Outer Regional & $32(6.9)$ & $10(7.69)$ & $25(7.67)$ & $(8.68)$ \\
\hline Remote & $3(0.65)$ & $10(7.69)$ & $18(5.52)$ & (1.73) \\
\hline Unknown & $33(7.11)$ & $82(63.08)$ & $224(68.71)$ & \\
\hline \multicolumn{5}{|l|}{ At Least One } \\
\hline Chronic Health Issue & $267(57.54)$ & $69(26.64)$ & $190(73.36)$ & n.a. \\
\hline Prior Breast Cancer & $16(3.51)$ & $5(31.25)$ & $11(68.75)$ & n.a. \\
\hline
\end{tabular}

Note:

Population distribution for Australia is based on all non-indigenous persons.

Abbreviation: n.a., not applicable. 
Table 3: Results of Latent Class Analysis (OR)

\begin{tabular}{|l|c|c|c|}
\hline Attributes & Prefer CPM & Traders & Prefer Monitoring \\
\hline Continuous variables: & & & \\
CBC Risk & $1.13(0.78-1.62)$ & $0.81(0.75-0.87)^{\mathrm{a}}$ & $0.97(0.75-1.25)$ \\
Other BC Risk & $0.98(0.88-1.1)$ & $0.96(0.94-0.99)^{\mathrm{b}}$ & $0.98(0.91-1.07)$ \\
Monitoring OOP, \$'00 & $1.01(0.91-1.11)$ & $0.95(0.93-0.98)^{\mathrm{a}}$ & $0.91(0.84-0.99)^{\mathrm{b}}$ \\
Surgery OOP, \$'00 & $0.99(0.99-1)$ & $0.99(0.99-1)^{\mathrm{a}}$ & $0.99(0.98-1)^{\mathrm{b}}$ \\
Pain Risk & $1.03(0.99-1.08)$ & $0.99(0.98-1)^{\mathrm{b}}$ & $1(0.97-1.04)$ \\
Sensitivity Risk & $1(0.95-1.05)$ & $0.99(0.98-1)$ & $0.99(0.95-1.03)$ \\
Categorical variables: & $1.27(0.84-1.94)$ & $1.08(0.97-1.21)$ & $1.26(0.93-1.72)$ \\
Ultrasound: Mammogram & $1.1(0.71-1.69)$ & $1.04(0.94-1.16)$ & $0.89(0.65-1.23)$ \\
MRI: Mammogram & $1.29(0.8-2.09)$ & $0.93(0.83-1.05)$ & $0.87(0.6-1.27)$ \\
Annual: Biannual Checks & $0.96(0.63-1.47)$ & $1.06(0.96-1.17)$ & $1.08(0.81-1.44)$ \\
Biennial: Biannual Checks & $1.11(0.83-1.5)$ & $1.14(1.05-1.23)^{\mathrm{b}}$ & $0.96(0.76-1.21)$ \\
Involved Always: Rarely & $0.24(0.05-1.14)^{\mathrm{c}}$ & $0.83(0.59-1.17)$ & $5.26(2.24-12.34)^{\mathrm{a}}$ \\
Monitoring: CPM & & & \\
\hline
\end{tabular}

Notes: $\quad \mathrm{c}<0.10$; b $p<0.05$; a $p<0.01 . \quad 69 \%$ of respondents in the Prefer CPM class only ever chose CPM Only, a further 16\% chose Monitoring Only once, and the remaining respondents chose Monitoring Only at most three times. $83 \%$ of respondents in the Prefer Monitoring class always chose Monitoring Only, a further $15 \%$ making only one choice for CPM Only. All women in the Traders chose from both options (the minimum for either option being three of of 12 choices), with a slight preference for choosing Monitoring Only more frequently than CPM Only.

Base levels for effects coded categorical variables are shown in italics.

Models implemented with robust standard errors to account for the survey nature of the data and with 1,000 replications per analysis.

Fit statistics: $\quad 11,136$ observations over 464 respondents.

Akaike information criterion 3,617.46, Bayesian information criterion 4,100.44, and pseudo $\mathrm{R}^{2} 0.047$.

Abbreviations: $\mathrm{BC}$, breast cancer; $\mathrm{CBC}$, contralateral breast cancer; $\mathrm{CPM}$, contralateral prophylactic mastectomy; MRI, magnetic resonance imaging; OOP, out-of-pocket; OR, odds ratio. 
Preferences for contralateral prophylactic mastectomy

\section{Box 1: Example DCE Choice Set}

\section{SEE ACCOMPANYING PICTURE}

After each such choice scenario, women answered the question,

"Which one would you choose?

o Surgery to remove unaffected breast plus monitoring

o Routine monitoring only" 
Preferences for contralateral prophylactic mastectomy

Figure 1: Ratings of Attribute Importance

EJCC_Figure1PanelA

EJCC_Figure1PanelB 